\title{
Feasibility and Optimal Design of a Stand-Alone Photovoltaic Energy System for the Orphanage
}

\author{
Vincent Anayochukwu Ani \\ Department of Electronic Engineering, University of Nigeria (UNN), Nsukka 410001, Nigeria \\ Correspondence should be addressed to Vincent Anayochukwu Ani; vincent_ani@yahoo.com
}

Received 10 February 2014; Revised 2 April 2014; Accepted 10 April 2014; Published 30 April 2014

Academic Editor: Nuri Azbar

Copyright ( 2014 Vincent Anayochukwu Ani. This is an open access article distributed under the Creative Commons Attribution License, which permits unrestricted use, distribution, and reproduction in any medium, provided the original work is properly cited.

\begin{abstract}
Access to electricity can have a positive psychological impact through a lessening of the sense of exclusion, and vulnerability often felt by the orphanages. This paper presented the simulation and optimization study of a stand-alone photovoltaic power system that produced the desired power needs of an orphanage. Solar resources for the design of the system were obtained from the National Aeronautics and Space Administration (NASA) Surface Meteorology and Solar Energy website at a location of $6^{\circ} 51^{\prime} \mathrm{N}$ latitude and $7^{\circ} 35^{\prime} \mathrm{E}$ longitude, with annual average solar radiation of $4.92 \mathrm{kWh} / \mathrm{m}^{2} / \mathrm{d}$. This study is based on modeling, simulation, and optimization of energy system in the orphanage. The patterns of load consumption within the orphanage were studied and suitably modeled for optimization. Hybrid Optimization Model for Electric Renewables (HOMER) software was used to analyze and design the proposed stand-alone photovoltaic power system model. The model was designed to provide an optimal system configuration based on an hour-by-hour data for energy availability and demands. A detailed design, description, and expected performance of the system were presented in this paper.
\end{abstract}

\section{Introduction}

Isolated (remote) sites are locations far from the places where most people live and often lack grid power supply. The price of conventional energy sources in remote areas, such as candles, paraffin, gas, coal, and batteries, is often more expensive than in places where most people live because of the remoteness of retailers. Providing grid electricity in remote areas is often associated with higher costs to the grid supplier. Power may be supplied through stand-alone systems (serving just one or two users). These systems can provide power for domestic uses such as lighting, cooling, $\mathrm{TV}$, radio, and communication. The power may be generated from various resources, using diesel, biomass, wind, PV, or small hydrogenerators, or hybrid combinations of these resources. Depending on the characteristics of a specific use (i.e., the load profile) and the local supply options, the least cost solution for an orphanage may consist of any of the above options. The attraction of these sources lies primarily in their abundance and ready access. Many of the isolated areas lying remotely from the grid have a high potential of renewable energy with solar energy being the most abundant.

Solar home system (SHS) typically includes a photovoltaic (PV) module, a battery, a charge controller, wiring setup, and a DC/AC inverter. A standard small SHS can operate several lights, a television (black-and-white or coloured), a radio or cassette player, and a small fan. SHS can eliminate or reduce the need for candles, kerosene, liquid propane gas, and/or battery charging and provide increased convenience and safety, improved indoor air quality, and a higher quality of light than kerosene lamps for reading [1]. The size of the system (typically 10 to 100 Watts peak (Wp)) determines the number of "light hours" or "TV-hours" available. For example, a $35 \mathrm{Wp}$ SHS provides enough power for four hours of lighting from four $7 \mathrm{~W}$ lamps each evening, as well as several hours of television. There are more than 500,000 SHS now installed in rural areas of developing countries [2-7].

Orphanages are often located in an isolated area and access to electricity can bring tangible social and economic benefits to them. The possible benefits can include household 


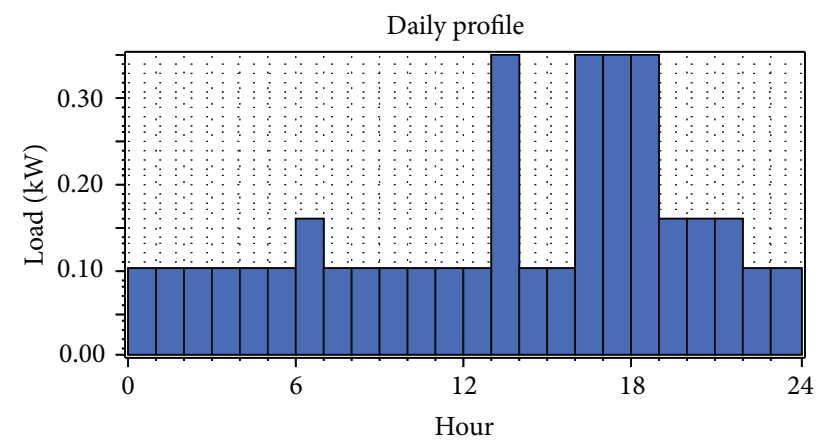

FIGURE 1: Load daily profile of typical orphanage electricity consumption.

(orphanage) lighting, the ability to refrigerate food and make washing clothes more convenient. The presence of electricity in an orphanage also can result in better reading culture. Finally, electricity can have a positive psychological impact through a lessening of the sense of exclusion and vulnerability often felt by orphanages, hence the need for the provision of an alternative sustainable electric power supply system. It is always convenient to perform a thorough simulation of the energy system to obtain an optimal output using the natural resources around it before its construction. Therefore, the purpose of this paper is to simulate and optimize a renewable (PV-battery) energy system that will produce the desired power needs of the orphanage, and the optimization parameter proposed here as a base is the offered service.

\section{Methodology}

In order to design a power system, one has to provide some information from the remote location of the orphanage such as the load profile that should be met by the system, solar radiation for PV generation, the initial cost of each component (PV panels, a charge controller, battery, and inverter), annual interest rate, and project lifetime.

2.1. The Reference Orphanage. From the acquired data, a profile of the orphanage was created. This profile consists of the orphanage load variations and electrical usage patterns within the orphanage. Figure 1 shows the daily profile electricity consumption in an orphanage in Nsukka (Enugu State, Nigeria). The orphanage in Nsukka is simple and does not require large quantities of electrical energy used for lighting and electrical appliances. Table 1 shows an estimation of each appliance's rated power, its quantity, and the hours of use by the orphanage in a single day.

\subsection{The Pattern of Using Electricity Power within the Orphan-} age. The lights in the orphanage will always be on as from $6 \mathrm{am}(06: 00 \mathrm{~h})$ to $7 \mathrm{am}(07: 00 \mathrm{~h})$. By this time $(6 \mathrm{am}$ to $7 \mathrm{am}$ ) the orphans start preparing for school. They leave the orphanage to school by $8 \mathrm{am}(08: 00 \mathrm{~h})$ and come back to the orphanage by $2 \mathrm{pm}(14: 00 \mathrm{~h})$. By $7 \mathrm{am}$, the light will go off, since the rays of light come in through the windows during

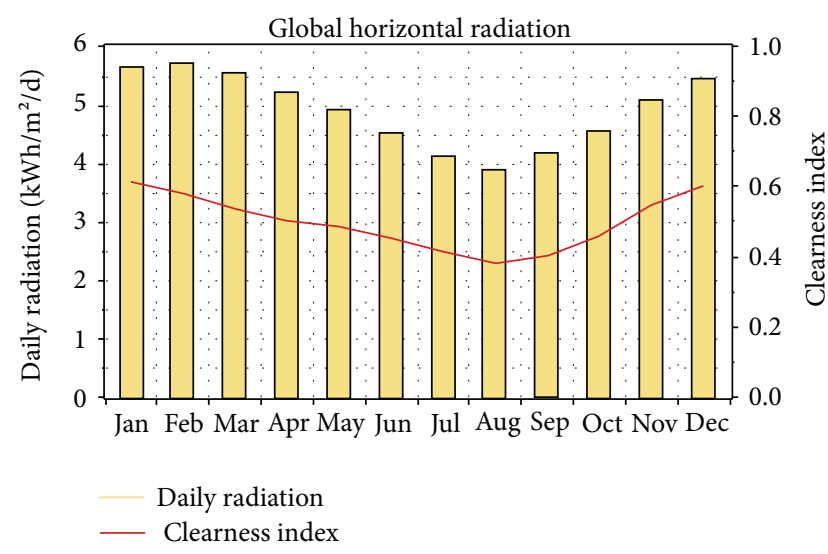

FIGURE 2: Graphics of monthly solar radiation profile for Nsukka.

day time [7 am-7 pm (07:00 h-19:00 h)]. The light comes on again by $7 \mathrm{pm}(19: 00 \mathrm{~h})$ till $10 \mathrm{pm}(22: 00 \mathrm{~h})$ to enable them to read their books. Once it is $10 \mathrm{pm}$, there will be light out and they will go to bed. The light out will be there till $6 \mathrm{am}$ before the light comes in again. Meanwhile, between $1 \mathrm{pm}$ $(13: 00 \mathrm{~h})$ and $2 \mathrm{pm}(14: 00 \mathrm{~h})$, when the radiation is at the apex, the washing machine will be used to wash orphans clothes. As from $4 \mathrm{pm}(16: 00 \mathrm{~h})$, the orphans will be in the waiting room watching television (programmes from the satellite dish), while the television, the satellite decoder, and the fans will all be ON till $7 \mathrm{pm}$. Once it is $7 \mathrm{pm}$, they will go and read their books till $10 \mathrm{pm}$.

2.3. Study Area. This research focuses on the simulation of photovoltaic power generation system for an orphanage sited in Nsukka located in a valley with poor wind but good solar energies. It is geographically located at $6^{\circ} 51^{\prime} \mathrm{N}$ latitude and $7^{\circ} 35^{\prime} \mathrm{E}$ longitude with annual average solar radiation of $4.92 \mathrm{kWh} / \mathrm{m}^{2} / \mathrm{d}$. The data for solar resource were obtained from the National Aeronautics and Space Administration (NASA) Surface Meteorology and Solar Energy website [8]. For this study, only solar PV technology was considered. Figure 2 shows the solar resource profile of this location. February is the sunniest month of the year. During this month, the solar energy resource is $5.7 \mathrm{kWh} / \mathrm{m}^{2} / \mathrm{d}$ while in August it is only $3.9 \mathrm{kWh} / \mathrm{m}^{2} / \mathrm{d}$. In the months of September, October, November, December, January, and February, the solar radiation increases with differences from month to month as (0.28), (0.38), (0.54), (0.35), (0.22), and (0.06), respectively, whereas in the months of March, April, May, June, July, and August, the solar radiation decreases with differences from month to month as (0.17), (0.32), (0.31), $(0.4),(0.4)$, and $(0.23)$, respectively. These differences will be considered during system sizing.

\section{Modeling of Energy System Components}

The mathematical model of the proposed energy system components contains photovoltaic system with battery storage 
TABLE 1: The electrical load data.

\begin{tabular}{|c|c|c|c|c|}
\hline Description of item & Qty & Load (watts per unit) & $\begin{array}{c}\text { Load (watts) } \\
\text { total }\end{array}$ & $\begin{array}{c}\text { Daily hours of actual } \\
\text { utilization (hr. per day) }\end{array}$ \\
\hline Television & 1 & 80 & 80 & $\begin{array}{c}3 \mathrm{hrs.} \\
\text { (16:00 hr.-19:00 hr.) }\end{array}$ \\
\hline Satellite decoder & 1 & 20 & 20 & $\begin{array}{c}3 \mathrm{hrs.} \\
\text { (16:00 hr.-19:00 hr.) }\end{array}$ \\
\hline Fan & 2 & 75 & 150 & $\begin{array}{c}3 \text { hrs. } \\
(16: 00 \text { hr. }-19: 00 \mathrm{hr} .)\end{array}$ \\
\hline Electric bulb (lighting) & 4 & 15 & 60 & $\begin{array}{c}4 \text { hrs. } \\
\text { (19:00 hr.-22:00 hr.); } \\
\text { (06:00 hr-07:00 hr.) }\end{array}$ \\
\hline Refrigerator & 1 & 100 & 100 & $\begin{array}{c}24 \text { hrs. } \\
\text { (0:00 hr. }-23: 00 \text { hr.) }\end{array}$ \\
\hline Washing machine & 1 & 250 & 250 & $1 \mathrm{hr} .(13: 00 \mathrm{hr} .-14: 00 \mathrm{hr})$. \\
\hline
\end{tabular}

system. The theoretical aspects are given below and based on [9-11].

Mathematical Model of Solar Photovoltaic. Using the solar radiation available, the hourly energy output of the PV generator $\left(E_{\mathrm{PV}}\right)$ can be calculated according to the following equation $[9,12,13]$ :

$$
E_{\mathrm{PV}}=G(t) \times A \times P \times \eta_{\mathrm{PV}},
$$

where $G(t)$ is the hourly irradiance in $\mathrm{kWh} / \mathrm{m}^{2}, A$ is the surface area in $\mathrm{m}^{2}, P$ is the $\mathrm{PV}$ penetration level factor, and $\eta_{\mathrm{PV}}$ is the efficiency of PV generator.

Mathematical Model of Charge Controller. To prevent overcharging of a battery, a charge controller is used to sense when the batteries are fully charged and to stop or decrease the amount of energy flowing from the energy source to the batteries. The model of the charge controller is presented below [9]:

$$
\begin{gathered}
E_{\text {CC-OUT }}(t)=E_{\text {CC-IN }}(t) \times \eta_{\text {CC }} \\
E_{\text {CC-IN }}(t)=E_{\text {SUR-DC }}(t),
\end{gathered}
$$

where $E_{\mathrm{CC} \text {-OUT }}(t)$ is the hourly energy output from charge controller, $\mathrm{kWh}, E_{\mathrm{CC}-\mathrm{IN}}(t)$ is the hourly energy input to charge controller, $\mathrm{kWh}, \eta_{\mathrm{CC}}$ is the efficiency of a charge controller, and $E_{\text {SUR-DC }}(t)$ is the amount of surplus energy from DC sources, $\mathrm{kWh}$.

Mathematical Model of Battery Bank. The battery state of charge (SOC) is the cumulative sum of the daily charge/discharge transfers. The battery serves as an energy source entity when discharging and a load when charging. At any hour $t$ the state of the battery is related to the previous state of charge and to the energy production and consumption situation of the system during the time from $t-1$ to $t$.

During the charging process, when the total output from renewable sources exceeds the load demand, the available battery bank capacity at hour $t$ can be described by $[9,12-14]$

$$
E_{\mathrm{BAT}}(t)=E_{\mathrm{BAT}}(t-1)-E_{\mathrm{CC}-\mathrm{OUT}}(t) \times \eta_{\mathrm{CHG}},
$$

where $E_{\mathrm{BAT}}(t)$ is the energy stored in the battery at hour $t$, $\mathrm{kWh}, E_{\mathrm{BAT}}(t-1)$ is the energy stored in the battery at hour $t-1, \mathrm{kWh}$, and $\eta_{\mathrm{CHG}}$ is the battery charging efficiency.

On the other hand, when the load demand is greater than the available energy generated, the battery bank is in discharging state. Therefore, the available battery bank capacity at hour $t$ can be expressed as $[9,12-14]$

$$
E_{\mathrm{BAT}}(t)=E_{\mathrm{BAT}}(t-1)-E_{\mathrm{Needed}}(t) \text {, }
$$

where $E_{\text {Needed }}(t)$ is the hourly load demand or energy needed at a particular period of time.

Let $d$ be the difference between minimum allowable SOC voltage limit and the maximum SOC voltage across the battery terminals when it is fully charged which is equal to 1 - DOD/100.

So, the depth of discharge (DOD) is as follows:

$$
\mathrm{DOD}=(1-d) \times 100 \text {. }
$$

DOD is a measure of how much energy has been withdrawn from a storage device, expressed as a percentage of full capacity. The maximum value of SOC is 1 , and the minimum SOC measured in percentage is determined by maximum depth of discharge (DOD):

$$
\mathrm{SOC}_{\mathrm{Min}}=1-\frac{\mathrm{DOD}}{100} \text {. }
$$

Mathematical Model of Inverter. In the proposed scheme, the PV panel and battery systems are connected with DC bus while the electric loads are connected with $\mathrm{AC}$ bus as shown in Figure 3.

The inverter models for photovoltaic and battery bank are given below [15]:

$$
\begin{aligned}
& E_{\mathrm{PV}-\mathrm{INV}, \mathrm{BAT}-\mathrm{INV}}(t) \\
& \quad=\left(E_{\mathrm{PV}}(t)+\frac{E_{\mathrm{BAT}}(t-1)-E_{\mathrm{LOAD}}(t)}{\eta_{\mathrm{INV}} \times \eta_{\mathrm{DCHG}}}\right) \times \eta_{\mathrm{REC}},
\end{aligned}
$$

where $E_{\mathrm{PV}-\mathrm{INV} \text { BAT-INV }}(t)$ is the hourly energy output from inverter $\mathrm{kWh}, E_{\mathrm{BAT}}(t-1)$ is the energy stored in the battery 


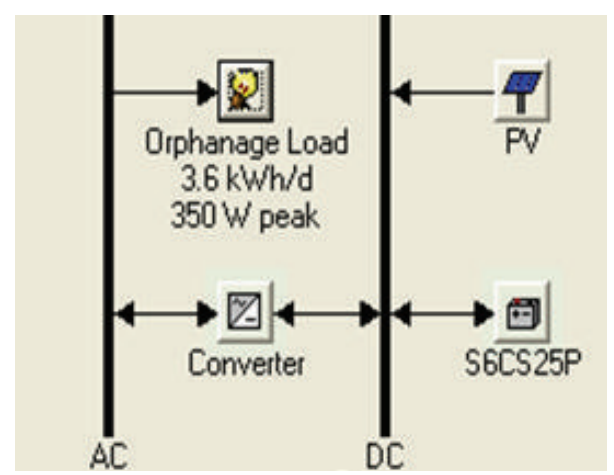

FIGURE 3: Schematic diagram of photovoltaic energy system.

at hour $t-1$, kWh, $E_{\text {Load }}(t)$ is the hourly energy consumed by the load side, $\mathrm{kWh}, \eta_{\mathrm{INV}}$ is the efficiency of inverter, and $\eta_{\text {DCHG }}$ is the battery discharging efficiency.

3.1. Power Generation Model. Total power generated at any time $t$ is given by $[9,12-14]$

$$
P(t)=\sum_{\mathrm{PV}=1}^{N_{P}} P_{\mathrm{PV}},
$$

where $N_{P}$ are number of PV cells. This generated power will feed the loads and when this generated power exceeds the load demand, then the surplus of energy will be stored in the battery bank. This energy (battery) will be used when a deficiency of power occurs to meet the load. The charged quantity of the battery bank has the constraint $\mathrm{SOC}_{\min } \leq$ $\operatorname{SOC}(t) \leq \mathrm{SOC}_{\max }$. The $\mathrm{SOC}_{\min }$ is at $40 \%$, while that of $\mathrm{SOC}_{\max }$ is at $80 \%$. The approach involves the minimization of a cost function subject to a set of equality and inequality constraints.

3.2. Cost Model (Economic and Environmental Costs) of Energy Systems. The equation for estimating the level of optimization of photovoltaic energy solution being considered for the orphanage and a location is derived as economic and environmental cost (carbon credit of $\mathrm{CO}_{2}$ ) model of running solar-photovoltaic + batteries and calculated as [15]

$$
\begin{aligned}
C_{\mathrm{ann}, \mathrm{tot}, \mathrm{s}+b}= & \sum_{s=1}^{N_{s}}\left(C_{\mathrm{acap}, s}+C_{\mathrm{arep}, s}+C_{\mathrm{aop}, s}+C_{\text {emissions }}\right) \\
& +\sum_{b=1}^{N_{b}}\left(C_{\mathrm{acap}, b}+C_{\mathrm{arep}, b}+C_{\mathrm{aop}, b}+C_{\text {emissions }}\right),
\end{aligned}
$$

where $C_{\text {acap,s }}$ is annualized capital cost of solar power, $C_{\text {arep }, s}$ is annualized replacement cost of solar power, $C_{\mathrm{aop}, s}$ is annualized operating cost of solar power, $C_{\text {emissions }}$ is cost of emissions, $C_{\text {acap }, b}$ is annualized capital cost of batteries power, $C_{\text {arep }, b}$ is annualized replacement cost of batteries power, and $C_{\mathrm{aop}, b}$ is annualized operating cost of batteries power.

The mathematical model derived in (9) estimates the life-cycle cost of the systems (solar-photovoltaic), which is
TABLE 2: Simulation results of electricity production, consumption, losses, and excess (kWh/yr).

\begin{tabular}{lc}
\hline Component & $\begin{array}{c}\text { Quantity } \\
\text { of } \\
\text { electricity } \\
(\mathrm{kWh} / \mathrm{yr})\end{array}$ \\
\hline Production from PV array & 1,916 \\
Losses from the battery & 122 \\
Losses from the inverter & 234 \\
Other losses such as cables & 52 \\
Consumption from AC load & 1,329 \\
Excess electricity & 179 \\
\hline
\end{tabular}

the total cost of installing and operating the system over its lifetime. The output when run with HOMER software/tool will give the optimal configuration of the energy system that takes into account technical and economic performance of supply options.

Net Present Cost (NPC) for Energy Systems. The total net present cost (NPC) of a system is the present value of all the costs that it incurs over its lifetime, minus the present value of all the revenue that it earns over its lifetime. Revenues include salvage value and grid sales revenue. The net present cost (NPC) for each component is derived using $[9,12-14,16,17]$

$$
C_{\mathrm{NPC}}=\frac{C_{\mathrm{ann}, \mathrm{tot}}}{\operatorname{CRF}\left(i, R_{\mathrm{proj}}\right)},
$$

where the capital recovery factor is $[9,12-14,16,17]$

$$
\mathrm{CRF}=\frac{i \cdot(1+i)^{N}}{(1+i)^{N}-1} .
$$

The economic optimization identifies the most financially attractive solution. For this research paper, HOMER version 2.8 beta has been used as the sizing and optimization software tool. It contains a number of energy component models and evaluates suitable technology options based on cost and availability of resources [18].

3.3. Configuration and Optimization of Stand-Alone Photovoltaic Energy System. Stand-alone photovoltaic system typically has an electricity generation device equipped with a wiring setup and supporting structure as well as the necessary BOS (balance of system) components (i.e., the battery bank, the charge controller, and the DC/AC inverter). The selection of components of energy system is done using Hybrid Optimization Model for Electric Renewables (HOMER) design software developed by the National Renewable Energy Laboratory, accurate enough to reliably predict system performance. HOMER is an optimization model, which performs many hundreds or thousands of approximate simulations in order to design the optimal system. The diagram of the completed stand-alone photovoltaic energy system can be seen in Figure 3. 
TABLE 3: Simulation results of economic cost.

\begin{tabular}{lccccc}
\hline Component & Capital $(\$)$ & Replacement $(\$)$ & O and M (\$) & ${ }^{*}$ Salvage $(\$)$ & 0 \\
PV & 2,800 & 0 & 1,606 & $-4,989$ & 4,406 \\
Surrette 6CS25P & 54,960 & 23,855 & 28 & 0 & 73,853 \\
Converter & 200 & 0 & 0 & $-4,989$ & 200 \\
System & 57,960 & 23,855 & 1,633 & 78,459 \\
\hline
\end{tabular}

* Salvage value is the value remaining in a component of the power system at the end of the project lifetime; that is, the salvage value of a component is directly proportional to its remaining life.

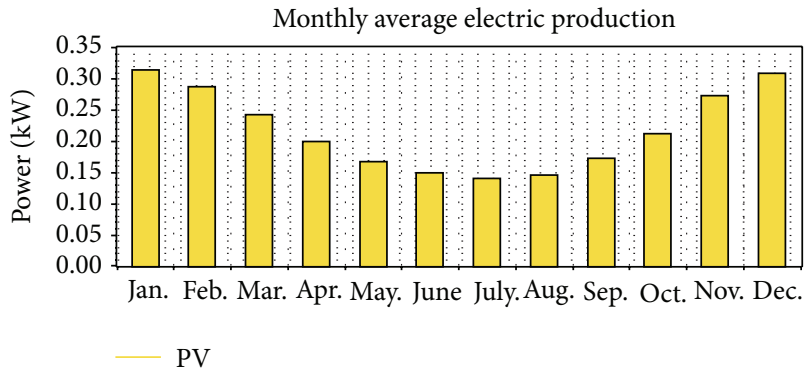

FIGURE 4: Electrical production of PV energy system.

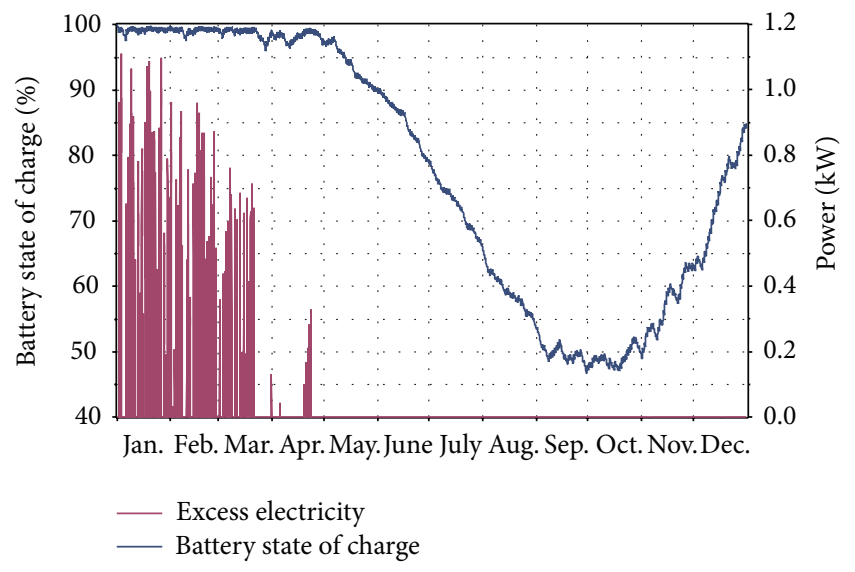

FIGURE 5: Battery state of charge versus excess electricity.

\section{Results and Discussion}

4.1. Results. The optimization result shows that sixteen solutions were simulated; one was feasible, which is PV-battery option with 1.4 kW PV, 48 Surrette 6CS25P battery, and $1 \mathrm{~kW}$ inverter; fifteen were infeasible due to the capacity shortage constraint. Twenty-four were omitted (twenty-two due to infeasibility, one for lacking a converter, and the remaining one for having an unnecessary converter). The obtained results provide information concerning the electricity production, consumption, losses, excess, and economic costs of the feasible system and are given in Tables 2 and 3 and shown in Figures 4, 5, and 6.

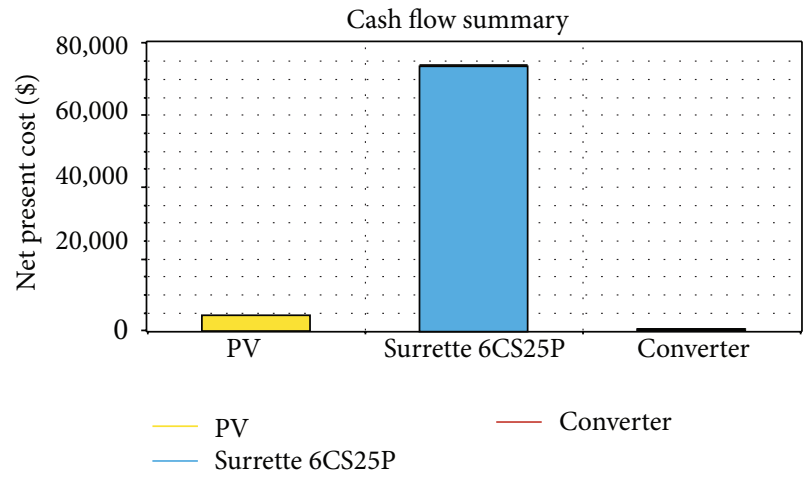

FIgURE 6: Net present cost of component of PV energy system.

\subsection{Discussion}

Electricity Production. The PV array in this orphanage generates $1,916 \mathrm{kWh}$ of electricity per year which effectively powers the load demand of 1,329 kWh per year with little excess electricity of $179 \mathrm{~kW}$ per year as shown in Table 2, and the electrical production of PV energy system is shown in Figure 4.

Losses from the System. A battery is used to store excess energy for later use. The conversion efficiency of batteries is not perfect and energy is usually lost as heat during chemical reaction, that is, during charging or recharging. Also, the amount of energy that will be delivered from the battery is managed by the inverter. The inverter connects directly to the battery bank and converts the direct current (DC) electrical energy from the battery bank to alternative current (AC) electrical energy, which is the energy that orphanages and most residential homes use. During the conversion, energy is also lost. Other losses, such as cables, were calculated and the amount of energy that is lost from the system was tabulated. From Table 2, it was shown that losses from the battery have a total of $122 \mathrm{kWh} / \mathrm{yr}$, losses from the inverter have a total of $234 \mathrm{kWh} / \mathrm{yr}$, and other losses have $52 \mathrm{kWh} / \mathrm{yr}$, making a grand total of $408 \mathrm{kWh} / \mathrm{yr}$ energy losses from the system as shown in Table 2.

Excess Electricity. Excess electricity always occurs when the battery state of charge (SOC) is at 98\% upwards and this is between Januaries and Aprils. As of May when the solar radiation is low, the battery is at $96 \%$ downward and discharges much and there will be no excess electricity from 


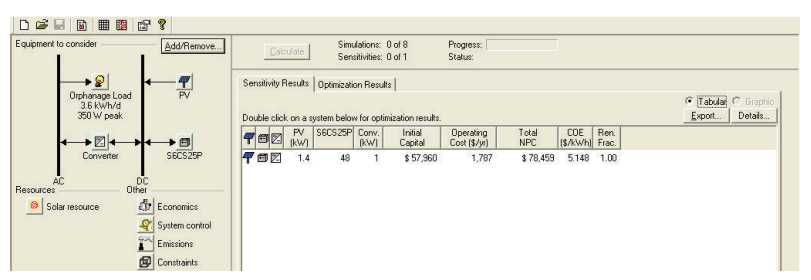

Figure 7: HOMER simulator diagram of photovoltaic energy system and the optimization results.

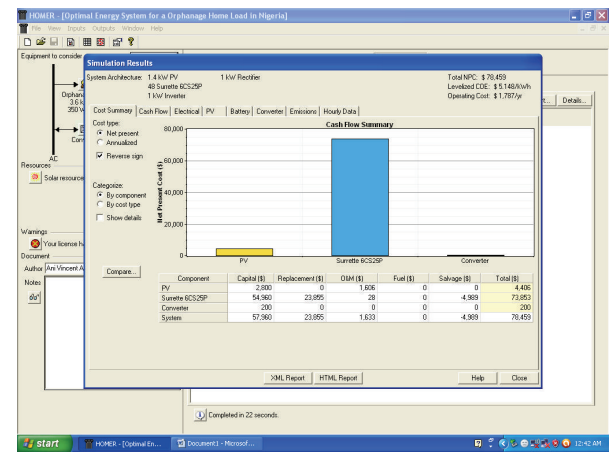

FIGURE 8: HOMER showing the simulation results of economic cost of component of PV energy system.

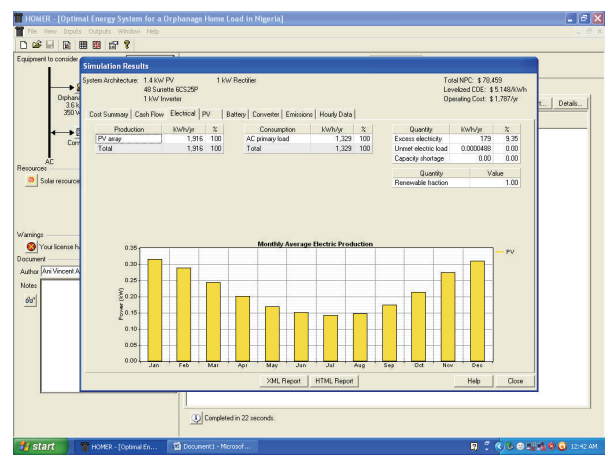

FIGURE 9: HOMER showing the electricity production of PV energy system.

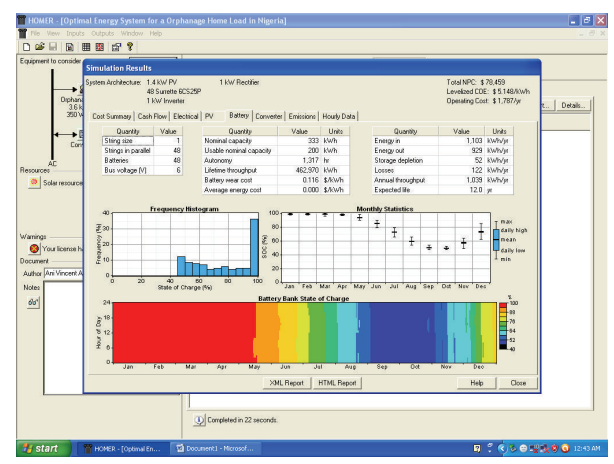

FIGURE 10: HOMER showing the battery state of charge and losses.

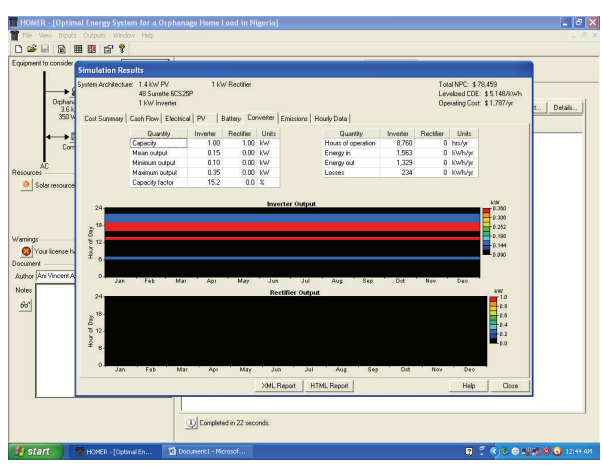

FIGURE 11: HOMER showing the inverter losses.

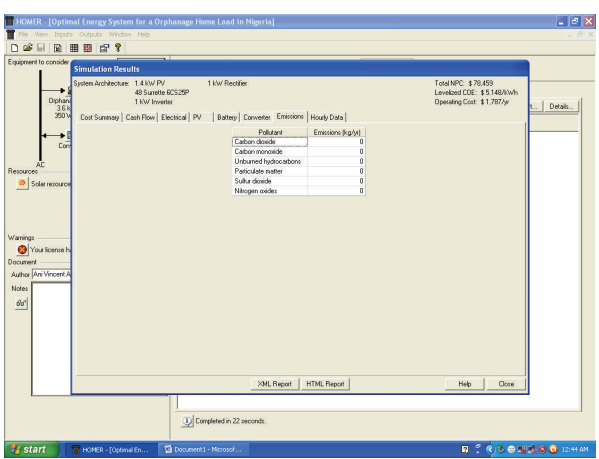

FIGURE 12: HOMER showing the result of the emissions.

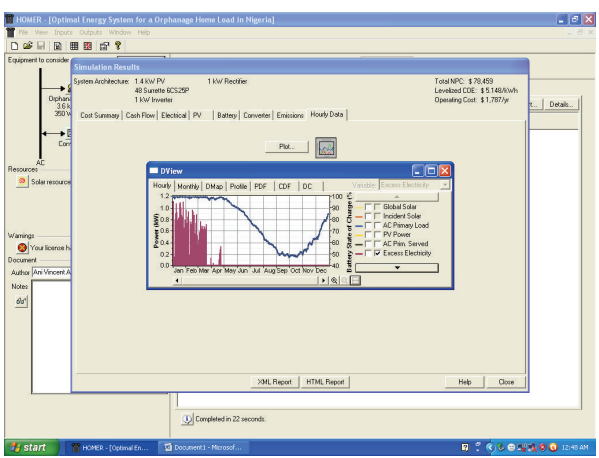

FIGURE 13: HOMER showing the battery state of charge versus excess electricity.

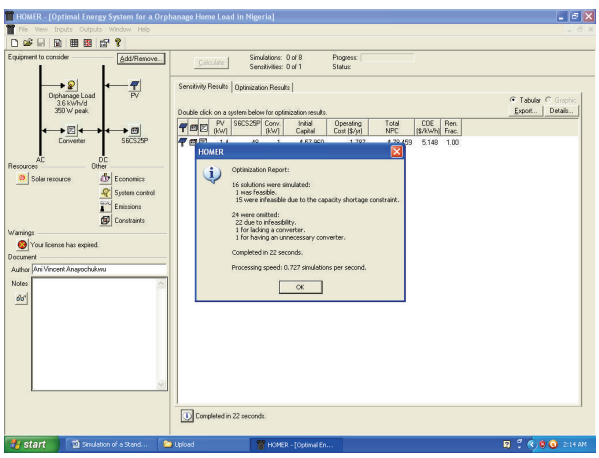

FIgURE 14: HOMER showing the optimization report. 
this point downward. The battery state of charge versus excess electricity is shown in Figure 5.

Economic Costs. Batteries are considered as a major cost factor in small-scale stand-alone power systems [15]. The optimization of the system is carried out by modifying the size of the batteries until a configuration that ensures sufficient autonomy was achieved with the least net present cost (NPC). The salvage value was used to calculate the annualized replacement cost. Battery is the only component that has replacement cost $(23,855 \$)$ and therefore has salvage value $(-4,989 \$)$ because it did not last till project lifetime and the replacement extended the estimated project lifetime which was deducted from the system cost $(73,853 \$)$ as shown in Table 3 and the net present cost of component of PV energy system is shown in Figure 6.

The software solutions showing the running program with the results are shown in Figures 7, 8, 9, 10, 11, 12, 13, and 14 .

\section{Conclusion}

The optimal design of PV/battery energy system was carried out minimizing the net present cost (NPC) by varying the size of the batteries until a configuration that produces the desired power needs of the orphanage is achieved. This optimization study indicates that energy requirements to provide electricity for an orphanage in Nigeria can be accomplished by $1.4 \mathrm{~kW}$ PV, 48 Surrette 6CS25P battery, and $1 \mathrm{~kW}$ inverter. The PV system is in significant mode during the day time, particularly in the dry season, but, at night and other cloudy days, the battery compensates. Due to the abundance of solar resource in Nigeria and having no environmental impact in terms of $\mathrm{CO}_{2}$, solar energy can be a choice for green power solutions in powering the orphanages located in remote areas.

\section{Abbreviations}

NASA: National Aeronautics and Space Administration

HOMER: Hybrid Optimization Model for Electric Renewables

SHS: $\quad$ Solar home system

PV: $\quad$ Photovoltaic

DC: $\quad$ Direct current

AC: $\quad$ Alternate current

SOC: $\quad$ State of charge

DOD: Depth of discharge

NPC: Net present cost

BOS: $\quad$ Balance of system

Min: Minimum

Max: Maximum.

Symbols

Wp: Watts peak

A: $\quad$ Surface area

kWh: Kilowatts hour $\mathrm{m}^{2}:$ Meter square

d: Day

$t$ : Time.

Greek Symbols

$\eta$ : Efficiency.

\section{Conflict of Interests}

The author declares that there is no conflict of interests regarding the publication of this paper.

\section{Acknowledgment}

The author would like to thank Professor Chinedu Ositadinma Nebo of Ministry of Power, Nigeria, for his useful discussion on the subject.

\section{References}

[1] H. Von, "Mini-grid system for rural electrification in the great Mekong sub-regional countries," in Renewable Energies and Energy Efficiency, vol. 6, University of Kassel, Kassel, Germany, 2007.

[2] F. Gerald, "Photovoltaic applications in rural areas of the developing world," Tech. Rep. no. 304, World Bank, Washington, DC, USA, 1995.

[3] A. Cabraal, M. Cosgrove Davies, and L. Schaeffer, "Best practices for photovoltaic household electrification programs: lessons from experiences in selected countries," Tech. Rep. no. 324, World Bank, Washington, DC, USA, 1996.

[4] A. Cabraal, M. Cosgrove Davies, and L. Schaeffer, "Accelerating sustainable photovoltaic market development," Progress in Photovoltaics: Research and Applications, vol. 6, no. 5, pp. 297-306, 1998.

[5] D. Kammen, "Promoting appropriate energy technologies in the developing world," Environment, vol. 41, no. 5, pp. 11-15, 3441, 1999.

[6] K. Kapadia, "Off-grid in Asia: the solar electricity business," Renewable Energy World, vol. 2, no. 6, pp. 22-33, 1999.

[7] G. Loois and B. van Hemert, Stand-Alone Photovoltaic Applications: Lessons Learned, James \& James, London, UK, 1999.

[8] NASA, 2013, https://eosweb.larc.nasa.gov/.

[9] V. A. Ani, "Optimal energy system for single household in Nigeria," International Journal of Energy Optimization and Engineering, vol. 2, no. 3, 26 pages, 2013.

[10] S. Ashok, "Optimised model for community-based hybrid energy system," Renewable Energy, vol. 32, no. 7, pp. 1155-1164, 2007.

[11] A. Gupta, R. P. Saini, and M. P. Sharma, "Steady-state modelling of hybrid energy system for off grid electrification of cluster of villages," Renewable Energy, vol. 35, no. 2, pp. 520-535, 2010.

[12] D. K. Lal, B. B. Dash, and A. K. Akella, "Optimization of PV/Wind/Micro-Hydro/diesel hybrid power system in homer for the study area," International Journal on Electrical Engineering and Informatics, vol. 3, no. 3, pp. 307-325, 2011.

[13] K. Sopian, A. Zaharim, Y. Ali, Z. M. Nopiah, J. A. Razak, and N. S. Muhammad, "Optimal operational strategy for hybrid 
renewable energy system using genetic algorithms," WSEAS Transactions on Mathematics, vol. 4, no. 7, pp. 130-140, 2008.

[14] H. Abdolrahimi and H. K. Karegar, "Optimization and sensitivity analysis of a hybrid system for a reliable load supply in Kish_Iran," International Journal of Advanced Renewable Energy Research, vol. 1, no. 4, pp. 33-41, 2012.

[15] V. A. Ani, Energy optimization at telecommunication base station sites [Ph.D. dissertation], University of Nigeria, Nsukka, Nigeria, 2013.

[16] V. A. Ani and A. N. Nzeako, "Energy optimization at GSM base station sites located in rural areas," International Journal of Energy Optimization and Engineering, vol. 1, no. 3, 31 pages, 2012.

[17] T. Lambert, "HOMER: The HybridOptimization Model for Electrical Renewables," 2009, http://www.nrel.gov/ international/tools/HOMER/homer.html.

[18] HOMER, 2013, http://www.nrel.gov/international/tools/ HOMER/homer.html. 


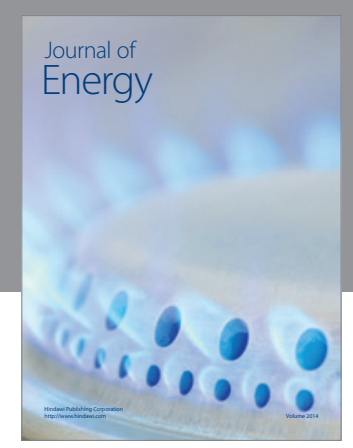

Journal of

Industrial Engineering
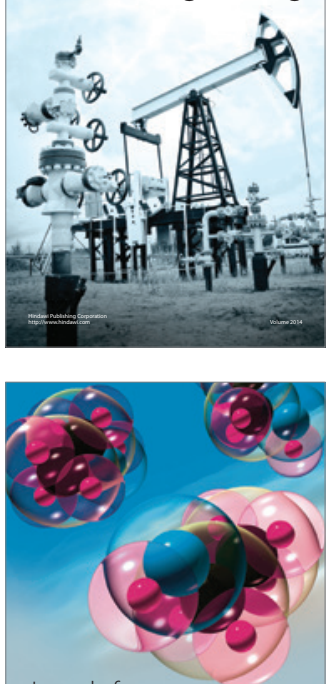

Fuels
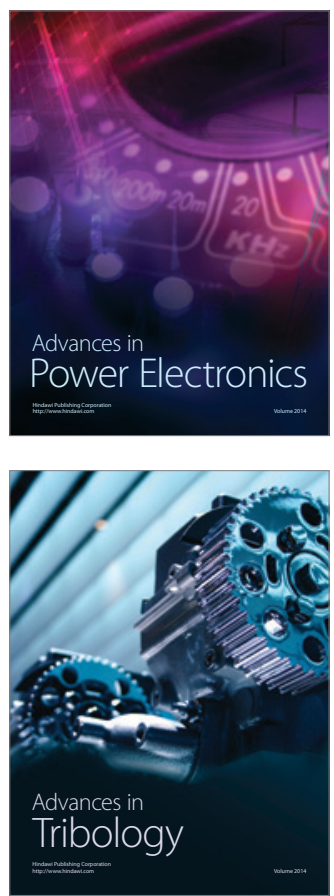

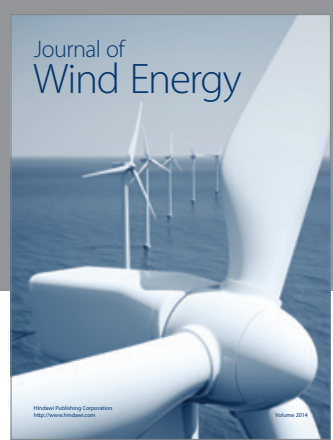

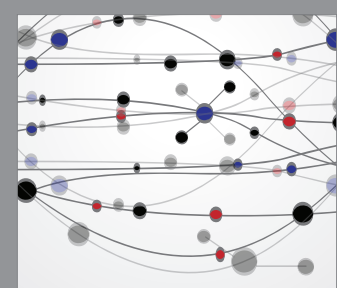

The Scientific World Journal

Submit your manuscripts at http://www.hindawi.com

Journal of

Structures
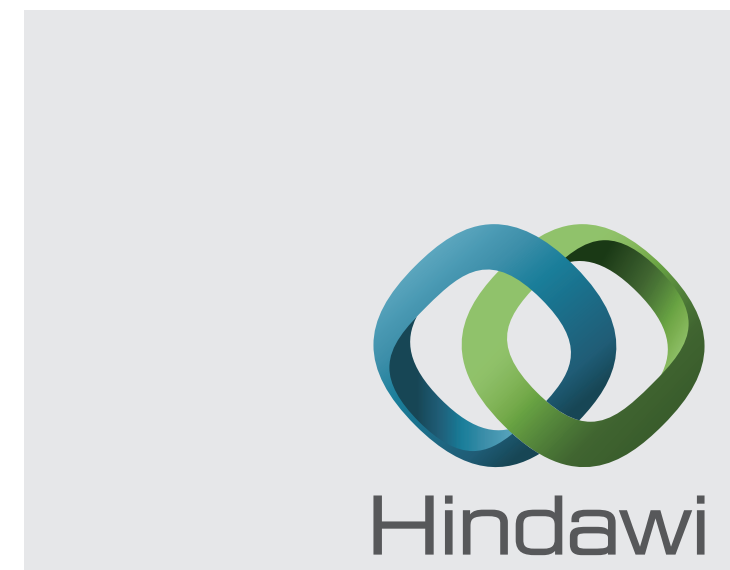

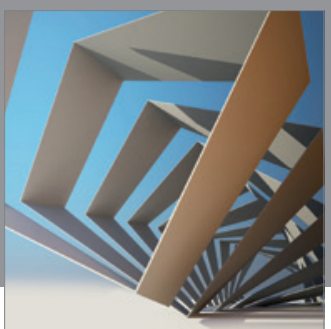

Rotating

Machinery
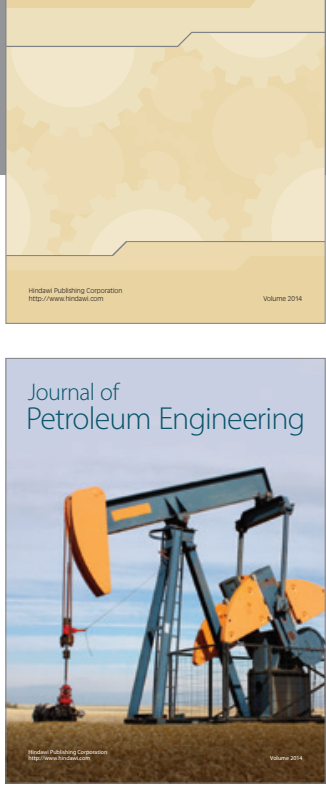

Journal of

Solar Energy
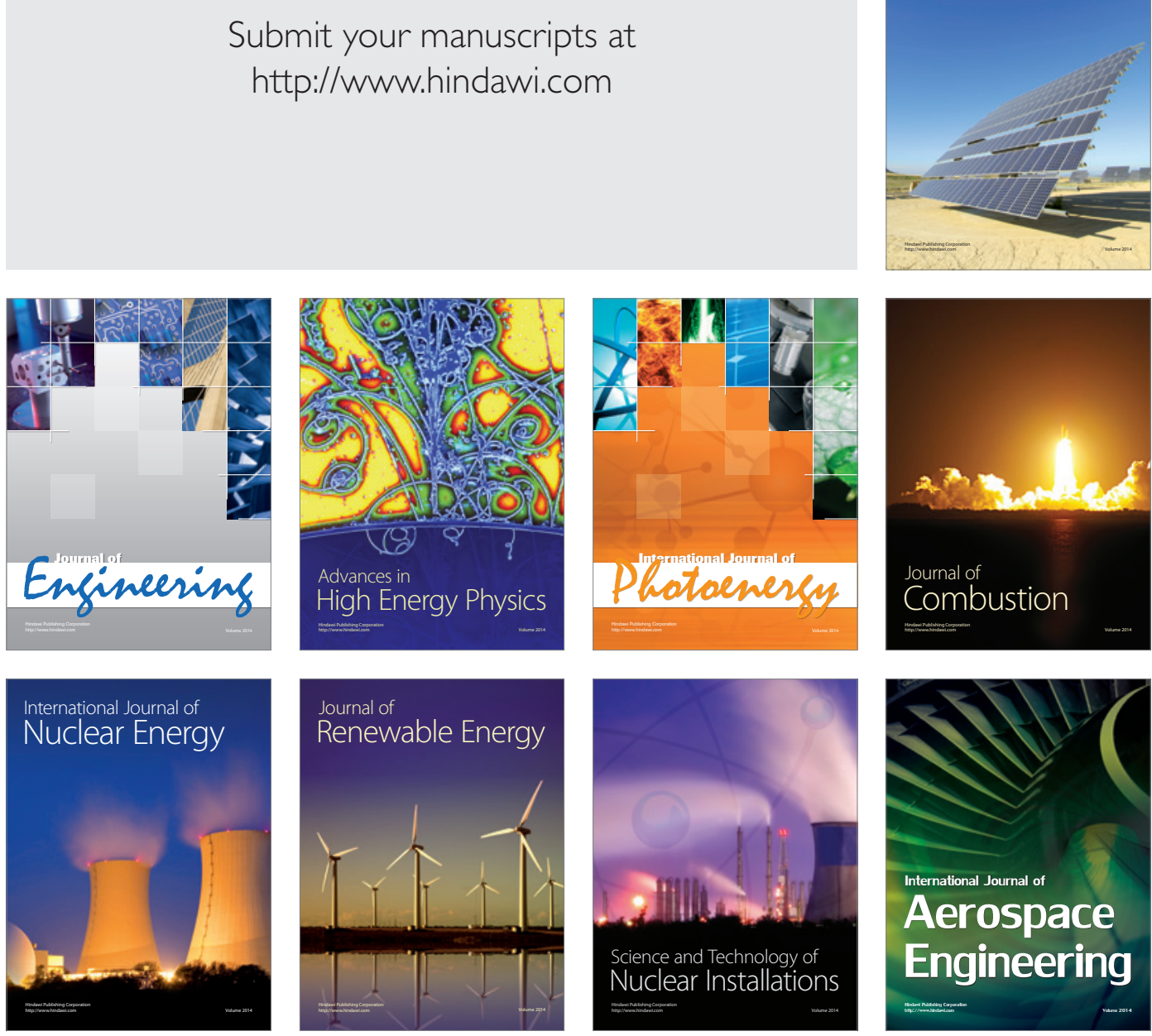